\title{
Genetic heterogeneity of autosomal dominant polycystic kidney disease in Argentina
}

D M Iglesias, R S Martín, A Fraga, M Virginillo, A R Kornblihtt, E Arrizurieta, M Viribay, J L San Millán, M Herrera, V Bernath

\begin{abstract}
Autosomal dominant polycystic kidney disease (ADPKD) is an inherited disorder with genetic heterogeneity. Up to three loci are involved in this disease, PKD1 on chromosome 16p13.3, PKD2 on 4q21, and a third locus of unknown location. Here we report the existence of locus heterogeneity for this disease in the Argentinian population by performing linkage analysis on 12 families of Caucasian origin. Eleven families showed linkage to PKD1 and one family showed linkage to PKD2. Two recombinants in the latter family placed the locus PKD2 proximal to D4S1563, in agreement with data recently published on the cloning of this gene. Analysis of clinical data suggests a milder ADPKD phenotype for the PKD2 family.

$(\mathcal{H}$ Med Genet 1997;34:827-830)
\end{abstract}

Keywords: polycystic kidney disease; genetic heterogeneity; linkage analysis

Instituto de

Investigaciones

Médicas Alfredo

Lanari, Universidad de

Buenos Aires, Donato

Alvarez 3150, 1427

Buenos Aires,

Argentina

D Iglesias

R Martín

A Fraga

M Virginillo

E Arrizurieta

Biología Molecular Diagnóstica SA,

Buenos Aires,

Argentina

M Herrera

V Bernath

INGEBI, Facultad de

Ciencias Exactas,

Universidad de Buenos

Aires, Argentina

A R Kornblihtt

Unidad de Genética Molecular, Hospital

Ramón y Cajal,

Madrid, Spain

$M$ Viribay

J L San Millán

Correspondence to: Dr Martin.

Received 4 December 1996 Revised version accepted for publication 13 May 1997
Autosomal dominant polycystic kidney disease (ADPKD) is one of the most common inherited disorders in humans, affecting 1 in 400 to 2400 in the Caucasian population. This disease is mainly characterised by progressive cystic dilatation of the renal tubules and other organs like the liver, spleen, and pancreas and is associated with both cardiac abnormalities and intracranial aneurysms. ${ }^{\prime}$ In Argentina, ADPKD is the underlying cause of renal failure in $7.2 \%$ of patients with end stage renal disease (ESRD). Approximately $51 \%$ of PKD patients enter renal failure by the age of $70 .^{2}$

ADPKD is genetically heterogeneous, with evidence of three different loci involved. The first ADPKD locus to be mapped was PKD1, which was localised to $16 \mathrm{p} 13.3 .^{3}$ Since then, many authors have reported several families unlinked to chromosome 16 . A second ADPKD locus, PKD2, has been linked to $4 \mathrm{q} 12-22 .{ }^{45}$ Recently, families with ADPKD unlinked to PKD1 or PKD2 loci have been described. ${ }^{6}$ PKD1 accounts for approximately $85 \%$ of ADPKD and is a more severe condition than PKD2, with an average age of ESRD of 56 years compared to 70 for PKD2. ${ }^{7}$ However, the phenotypic heterogeneity observed in ADPKD is not only explained by different disease genes, since considerable clinical variability within families and clinical anticipation have been described.

Candidate genes for $\mathrm{PKD} 1$ and $\mathrm{PKD} 2$ have been recently identified by positional cloning. ${ }^{8-10}$ PKD1 is predicted to encode a protein, polycys- tin, of $4302 / 3$ amino acids. Polycystin is a membrane protein with multiple extracellular domains and a membrane associated C-terminal region. The predicted 986 amino acid sequence of the PKD2 gene product has six transmembrane spans with intracellular amino- and carboxy-termini. The PKD2 protein contains a potential calcium binding domain and shows similarity with part of the membrane associated region of PKD1. This similarity, together with the close pattern of clinical symptoms exhibited, suggests that PKD1 and PKD2 could function in a parallel pathway or even could form complexes. ${ }^{10}$ Extensive mutation searching in

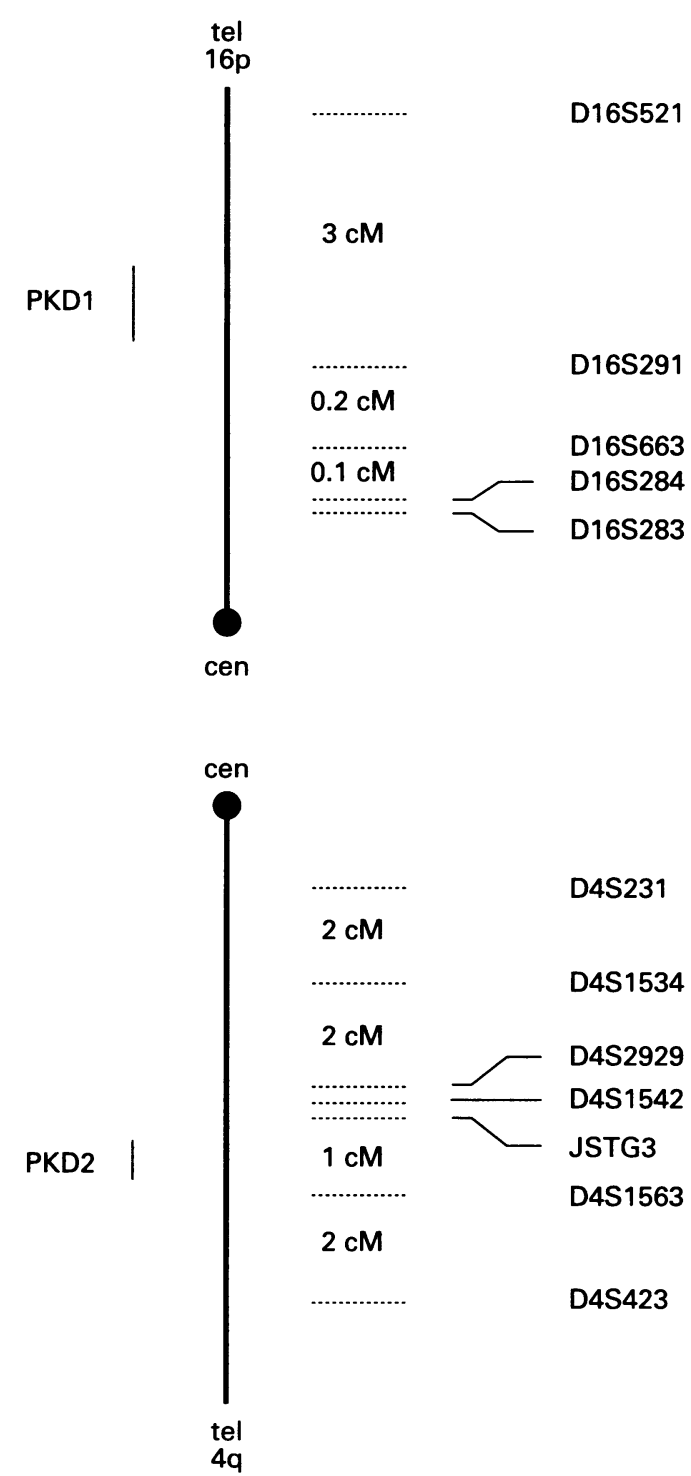

Figure 1 Map of the microsatellite markers around the PKD1 (16p13.3) and PKD2 (4q21) genes. Approximate intermarker distances are given. 
PKD1 and preliminary results in PKD2 indicate a high degree of allelic heterogeneity. In this context linkage analysis remains an important approach to studying the genetics of ADPKD.

We report here the first molecular genetic study of ADPKD in Argentina. Linkage analysis in 12 affected families with microsatellite markers close to PKD1 or PKD2 showed the existence of locus heterogeneity in our population, as has been found in other related Caucasian populations.

\section{Material and methods}

PATIENTS AND FAMILY DATA

Patients were clinically evaluated at the Instituto de Investigaciones Médicas Alfredo Lanari, Universidad de Buenos Aires. Twelve families agreed to participate in this study, with informed consent, for DNA isolation and ultrasound studies and the protocol was approved by our local ethics committee. Ultrasound investigation and DNA characterisation were performed only after expressed willingness of the people concerned and the parents in the case of children at risk. The total number of people investigated was 142 (12 index cases and 130 relatives). In each case a minimum of two generations with at least two affected members were analysed. Family members were considered positive for ADPKD when one cyst in one kidney and at least two cysts in the other were found, according to the criteria defined by Bear et al. ${ }^{11}$
DNA ANALYSIS

Genomic DNA was extracted from peripheral leucocytes by standard procedures. All families were typed for five microsatellites linked to PKD1, four of them proximal to the disease gene, D16S284, D16S283, ${ }^{12} \mathrm{D} 16$ S291, ${ }^{13}$ and D16S663, ${ }^{14}$ and one distal marker, D16S521. Six microsatellites linked to PKD2 were analysed in a family (16012) that showed negative linkage to the $16 \mathrm{p} 13.3$ markers (fig 1 ). They were D4S231, ${ }^{15}$ D4S1534, D4S1563, D4S423, D4S1542, D4S2929, ${ }^{16}$ and JSTG3. ${ }^{10}$ Conditions for PCR amplification and gel electrophoresis were as recommended in the corresponding references.

DATA PROCESSING

Linkage analysis was performed on each family. Three point lod scores were calculated using the MLNK and ILINK options of LINKAGE package version 5.1, ${ }^{17}{ }^{18}$ kindly provided by Dr Ott. A gene frequency of 0.001 was assumed for PKD1 and 0.0001 for PKD2. For PKD1, three liability classes were performed considering our data and previous reports, ${ }^{71114}$ corresponding to gene penetrances of $0.64,0.92$, and 0.99 for age groups $0-10,10-30$, and over 30 years, respectively. For PKD2, the liability classes assumed were $0.50,0.85$, and 0.95 for age groups $0-20$, $20-30$, and over 30 years respectively. ${ }^{19}$ Linkage calculations were carried out under the assumption of no differences in the female/male recombination rate and the absence of genetic interference. Distances between the markers

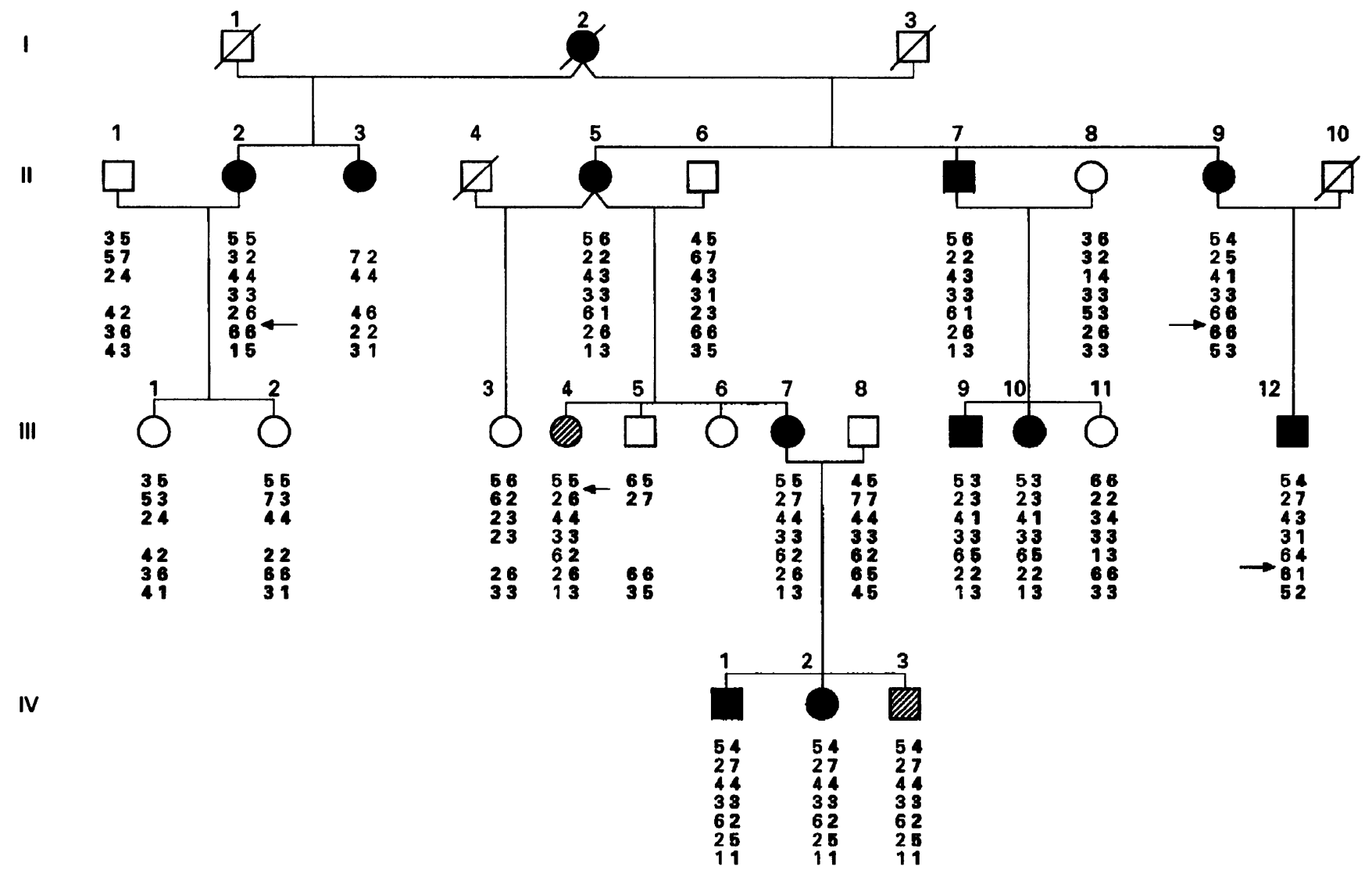

Figure 2 Segregation of chromosome 4 markers in family 16012. Black boxes indicate the affected members, shaded boxes represent people not clinically tested who have inherited the affected haplotype, and diagonal lines show family members who have died. Numbers arbitrarily chosen indicate alleles for the polymorphic markers used (top to bottom): D4S231, D4S1534, D4S2929, D4S1542, FSTG3, D4S1563, and D4S423. Arrows between loci indicate recombinant haplotypes. 
Table 1 Results of multipoint linkage analysis in 12 Argentinian ADPKD families. Lod score values for linkage between PKD and two loci flanking the PKD1 region were calculated using LINKMAP with a fixed order of marker loci and considering 10 intervals for calculations as follows: (D16S283 D16S663 - D16S291) - 0.035-D16S521. Previous physical and genetic studies have shown that the PKD1 locus lies close but distal to the cluster (D16S283 - D16S663 - D16S291). ${ }^{14}$ The resulting family lod scores were then analysed for linkage heterogeneity using the HOMOG program. ${ }^{21}$ Conditional probabilities for linkage to PKD1 for each family are presented

\begin{tabular}{|c|c|c|c|c|c|c|c|c|c|c|c|c|}
\hline \multirow[b]{2}{*}{ Family } & \multicolumn{11}{|c|}{ Recombination fraction } & \multirow{2}{*}{$\begin{array}{l}\text { Conditional } \\
\text { probabilities } \\
\text { for linkage }\end{array}$} \\
\hline & 0.0000 & 0.0035 & 0.0070 & 0.0105 & 0.0104 & 0.0175 & 0.0210 & 0.0245 & 0.0280 & 0.0315 & 0.0350 & \\
\hline 16001 & 1.04 & 0.99 & 0.94 & 0.88 & 0.81 & 0.73 & 0.63 & 0.51 & 0.33 & 0.03 & -1.81 & 0.981 \\
\hline 16002 & 1.79 & 1.75 & 1.72 & 1.69 & 1.65 & 1.62 & 1.58 & 1.54 & 1.49 & 1.45 & 1.40 & 0.997 \\
\hline 16003 & 1.78 & 1.78 & 1.78 & 1.78 & 1.78 & 1.78 & 1.78 & 1.78 & 1.78 & 1.78 & 1.78 & 0.998 \\
\hline 16004 & 1.20 & 1.20 & 1.19 & 1.19 & 1.19 & 1.18 & 1.18 & 1.18 & 1.18 & 1.17 & 1.17 & 0.992 \\
\hline 16005 & 1.19 & 1.16 & 1.14 & 1.11 & 1.08 & 1.05 & 1.02 & 0.99 & 0.96 & 0.92 & 0.88 & 0.991 \\
\hline 16006 & 1.43 & 1.38 & 1.33 & 1.27 & 1.20 & 1.12 & 1.02 & 0.90 & 0.72 & 0.43 & -0.99 & 0.995 \\
\hline 16008 & 1.13 & 1.13 & 1.13 & 1.13 & 1.13 & 1.13 & 1.13 & 1.13 & 1.13 & 1.13 & 1.13 & 0.992 \\
\hline 16009 & 1.57 & 1.56 & 1.55 & 1.54 & 1.53 & 1.53 & 1.52 & 1.51 & 1.51 & 1.50 & 1.50 & 0.996 \\
\hline 16010 & 0.60 & 0.59 & 0.59 & 0.58 & 0.58 & 0.58 & 0.57 & 0.57 & 0.56 & 0.56 & 0.55 & 0.971 \\
\hline 16011 & 0.30 & 0.30 & 0.30 & 0.30 & 0.31 & 0.31 & 0.31 & 0.30 & 0.30 & 0.30 & 0.30 & 0.948 \\
\hline 16012 & $-\infty$ & -6.98 & -6.48 & -6.24 & -6.13 & -6.09 & -6.13 & -6.24 & -6.48 & -6.98 & $-\infty$ & 0.000 \\
\hline
\end{tabular}

and the PKD loci were as published, ${ }^{5}{ }^{20}$ except for D16S521 which was calculated from the families analysed in this study. Multipoint analysis was run using LINKMAP with a fixed order of marker loci and considering 10 intervals for calculation as follows: (D16S283 D16S663 - D16S291) - 0.035 - D16S521. Previous physical and genetic studies have shown that the PKD1 locus lies close but distal to the cluster (D16S283 - D16S663 D16S291). ${ }^{14}$ The resulting family lod scores were then analysed for linkage heterogeneity using the HOMOG program. ${ }^{21}$

\section{Results and discussion}

GENETIC AND LINKAGE ANALYSIS

Before the analysis of linkage in our population, we characterised the number of alleles, their sizes, polymorphism information content (PIC), and heterozygosity content of the markers described above, in a group of 22 to 68 unrelated controls. Marker characteristics did not differ from those already published for other Caucasian populations. ${ }^{12}$ The population of Argentina is mainly of Caucasian origin, predominantly from Europe. This could explain why no differences are present in the characteristics of the microsatellite markers used in this study, as compared to those already published.

Multipoint linkage analysis was performed in 12 families using LINKMAP (table 1). The lod score values obtained were used to test locus heterogeneity using the HOMOG program. The $\log (\ln )$ likelihood on the assumption of linkage homogeneity (H1) was 15.26 compared with 24.34 on the assumption of linkage

Table 2 Genetic and clinical data from the 12 affected families. Association with end stage renal disease (ESRD) and ultrasonographically proven cysts are shown

\begin{tabular}{|c|c|c|c|c|c|c|c|c|}
\hline \multirow{2}{*}{$\begin{array}{l}\text { Age group } \\
(y)\end{array}$} & \multicolumn{4}{|c|}{ Members with an associated haplotype } & \multicolumn{4}{|c|}{ Members without an associated haplotyp } \\
\hline & $E S R D$ & No ERSD & Cysts & No cysts & $E S R D$ & No ERSD & Cysts & No cysts \\
\hline \multicolumn{9}{|l|}{ PKD1 } \\
\hline $0-10$ & 0 & 10 & 1 & 9 & 0 & 6 & 0 & 6 \\
\hline $10-20$ & 0 & 3 & 1 & 2 & 0 & 7 & 0 & 7 \\
\hline $20-30$ & 0 & 12 & 11 & 1 & 0 & 4 & 0 & 4 \\
\hline $\begin{array}{l}>30 \\
\text { PKD2 }\end{array}$ & 11 & 20 & 31 & 0 & 0 & 22 & 0 & 22 \\
\hline $0-10$ & 0 & 2 & 2 & 0 & 0 & 0 & 0 & 0 \\
\hline $10-20$ & 0 & 1 & 1 & 0 & 0 & 2 & 0 & 2 \\
\hline $20-30$ & 0 & 3 & 3 & 0 & 0 & 1 & 0 & 1 \\
\hline$>30$ & 0 & 8 & 8 & 0 & 0 & 4 & 0 & 4 \\
\hline
\end{tabular}

heterogeneity (H2) (one linked and one unlinked locus). The likelihood ratio ( $\mathrm{H} 2 v$ H1) was $8.7 \times 10^{3}$, which is significant $\left(\chi^{2}=8.15, p<0.0001\right)$, and the estimate of the fraction of PKD1 linked families, $\alpha$, was 0.9 , showing that linkage heterogeneity is present in our group of families. PKD1 was identified as the disease locus in 11 families (conditional probability of linkage higher than 0.9 in each case). The maximum multipoint lod score under heterogeneity $(\mathrm{Zmax}=12.05)$ was obtained by placing PKD1 in the interval close to the markers (D16S283-D16S663-D16S291).

Only one family (16012) showed statistically significant evidence of non-linkage to PKD1, with a conditional probability of 0.00 (table 1 ). The analysis of chromosome 4 markers showed positive linkage to the PKD2 locus (fig 2). In this PKD2 family, two recombinant subjects between the closely positioned markers D4S1534 and D4S1563 were studied in detail. Analysis of patients II. 2 and II.9 with markers D4S1542, D4S2929, and JSTG3 (data taken from Genethon data base) placed the gene proximal to marker D4S1563 (fig 1), where the gene was recently identified. ${ }^{10}$

\section{CLINICAL ANALYSIS}

A total of 142 subjects were studied for the purpose of this report. Fifty-eight subjects were affected, 60 blood relatives were unaffected (at risk subjects), and 24 were spouses. No significant differences were seen in the number of male/female ADPKD patients (24 males $v 34$ females, $\chi^{2}=0.0197$, NS). We investigated 12 families affected with autosomal dominant polycystic kidney disease, 11 of which were linked to PKD1. The finding of only one family linked to PKD2 does not allow us to estimate the frequency of this form in our population. In the PKD1 families, all members over 30 years of age with affected relatives and a PKD1 associated haplotype had detectable cysts. No member entered ESRD below the age of 30 . Twelve subjects $(30 \%)$ developed chronic renal failure at a mean age of 46.2 years. However, members without the associated PKD1 haplotype did not enter ESRD or have cysts. Twelve subjects at risk between 0 and 30 years of age (nine between 0 and 10 years, two between 10 and 20 , and one between 20 and 30) carried the affected haplotype with- 
out evidence of cysts on ultrasound examination at the time of the study (table 2).

All members of the PKD2 family carrying a disease associated haplotype had cysts, independent of their age (table 2). No member of the PKD2 family needed dialysis or transplantation, even when studied at advanced ages. Our assessment of 21 subjects in four generations of this large family is consistent with previous observations that $\mathrm{PKD} 2$ patients present a more benign clinical form in comparison to PKD1 patients. ${ }^{7}$ In regard to the presence of cysts as related to age, PKD2 patients develop cysts earlier than PKD1 patients. Further investigation is needed to determine whether the severity of the disease and age related expression are different between PKDI and PKD2 types.

Based on the recently published sequences of both PKD1 and PKD2, we are currently identifying different mutations and their clinical correlates in the Argentine PKD population. However, reported mutations for PKD1 are heterogeneous and complex enough to suggest that linkage analysis will continue to be the most useful approach for the presymptomatic diagnosis of PKD in Argentina. We thank all the PKD family members and their physicians for their cooperation, Dr J Ott for providing us with LNNKAGE
software, Daniel Grinberg for his assistance with the LINKAGE software, Daniel Grinberg for his assistance with the LINKAGE program and interpretation of the data, Eliecer Coto for PKD1
markers, and Dorien Peters for the gift of unpublished marker markers, and Dorien Peters for the gift of unpublished marker
JSTG3. This work was partially supported by the Spanish JSTG3. This work was partially supported by the Spanish
Fondo de Investigaciones Sanitarias (JLSM) and a grant from Fondo de Investigaciones Sanitarias (JLSM) and a grant from the Secretaria de Ciencia y Técnica Argentina (PID N
PMT-SID 0262) (ARK and RSM). DMI has a research fellowship from the University of Buenos Aires.

1 Gabow PA. Autosomal dominant polycystic kidney disease. N Engl $\mathcal{Y}$ Med 1993;329:332-42.

2 Registro Latinoamericano de Diálisis y Transplante Renal. Sociedad Latinoamericana de Nefrología, Comité de Registro, Montevideo,Uruguay, 1994

3 Reeders ST, Breuning MH, Davies KE, et al. A highly polymorphic DNA marker linked to adult polycystic kidney disease on chromosome 16. Nature 1985;317:542-4.
4 Kimberling WJ, Kumar S, Gabow PA, Kenyon JB, Connolly CJ, Somlo S. Autosomal dominant polycystic kidney disease: localization of a second gene to chromosome 4q13-q23. Genomics 1993;18:467-72.

5 Peters DJ, Spruit I, Saris J, et al. Chromosome 4 localization of a second gene for autosomal dominant polycystic kidney disease. Nat Genet 1993;5:359-62.

6 Daoust MC, Reynolds DM, Bichet DG, Somlo S. Evidence for a third genetic locus for autosomal dominant polycystic kidney disease. Genomics 1995;25:733-6.

7 Parfrey PS, Bear JC, Morgan J, et al. The diagnosis and prognosis of autosomal dominant polycystic kidney disease. N Engl f Med 1990;323:1085-90.

8 The European Polycystic Kidney Disease Consortium. The polycystic kidney disease 1 gene encodes a $14 \mathrm{~kb}$ transcript and lies within a duplicated region on chromosome 16 . Cell 1994;77:881-94.

9 The International Polycystic Kidney Disease Consortium. Polycystic kidney disease: the complete structure of the PKD1 gene and its protein. Cell 1995;81:289-98.

10 Mochizuki T, Wu G, Hayashi T, et al. PKD2, a gene for polycystic kidney disease that encodes an integral membrane protein. Science 1996;272:339-42.

11 Bear JC, McManamon P, Morgan J, et al. Age at clinical onset and at ultrasonographical detection of adult polycystic kidney disease: data for genetic counselling. $A m$ F Med Genet 1984;18:45-53.

12 Harris PC, Thomas S, Ratcliffe PJ, Breuning MH, Coto E, Lopez-Larrea C. Rapid genetic analysis of families with polycystic kidney disease 1 by means of a microsatellite polycystic kidney disease 1 by mea

13 Thompson AD, Shen Y, Holman K, Sutherland GR, Calle DF, Richards RI. Isolation and characterisation of (AC) microsatellite genetic markers from human chromosome 16. Genomics 1992;13:402-8.

14 Peral B, Ward CJ, San Millán JL, et al. Evidence of linkage disequilibrium in the Spanish polycystic kidney disease 1 population. Am ₹ Hum Genet 1994;54:899-908.

15 Mills KA, Buetow KH, Xu Y, et al. Genetic and physical maps of human chromosome 4 based on dinucleotide repeats. Genomics 1992;14:209-19.

16 Dib C, Faure S, Fizames C, et al. A comprehensive map of the human genome based on 5,264 microsatellites. Nature 1996;380:152-4.

17 Lathrop GM, Lalouel JM, Julier C, Ott J. Strategies for multilocus linkage analysis in humans. Proc Natl Acad Sci USA 1984;81:3443-6.

18 Terwilliger JD, Ott J. Handbook of human genetic linkage. Baltimore: The Johns Hopkins University Press, 1994.

19 San Millán JL, Viribay M, Peral B, Martinez I, Weissenbach J, Moreno F. Refining the localization of the PKD2 locus on chromosome $4 \mathrm{q}$ by linkage analysis in Spanish families on chromosome 4q by linkage analysis in Spanish families with autosomal dominant polycystic

20 Somlo S, Wirth B, Germino GG, et al. Fine genetic localization of the gene for autosomal dominant polycystic kidney disease (PKD1) with respect to physically mapped markers. Genomics 1992;13:152-8.

21 Ott J. Analysis of human genetic linkage. Baltimore: The John Hopkins University Press, 1991. 